\title{
Pragmatic person features in pronominal and clausal speech act phrases
}

\author{
Hailey Hyekyeong Ceong*
}

\begin{abstract}
This paper proposes the necessity of pragmatic person features (Ritter and Wiltschko 2018) in pronominal and clausal speech act phrases in Korean, giving three main arguments for such necessity: (i) pragmatic person [ADDRESSEE] is needed for hearsay mye which expresses the meaning of you told me without the lexical verb of saying, (ii) pragmatic person [SPEAKER] is needed for the unequal distribution of first-person plural pronouns with exhortative $c a$ 'let us', and (iii) pragmatic persons [SPEAKER], and [ADDRESSEE] are needed for the asymmetric distribution of a dative goal argument in secondhand exhortatives. Based on the compatibility and incompatibility of exhortative $c a$ - and secondhand exhortative $c a$ mye clauses with a first-person pronoun (e.g., na 'I', ce 'I', wuli 'we', and cehuy 'we'), I argue that pragmatic person features are needed in syntax to account for their distribution.
\end{abstract}

Keywords. person; formality; clusivity; speech act phrases; hearsay; Korean

1. Introduction. This paper investigates pragmatic person features in pronominal and clausal speech act phrases focusing on the properties of first-and secondhand exhortatives in Korean. Based largely on evidence from a survey of variable pronominal paradigms across languages, Ritter and Wiltschko (2018) state that some languages lexicalize the distinction between pragmatic and grammatical person features. In this paper, I argue, on the basis of the distribution and interpretation of first-and secondhand exhortative markers, first-person pronouns, and the (dis-) agreement with the head of exhortatives and a first-person pronoun, that the distinction is lexicalized in Korean as well.

Consider the distribution of two first-person plural pronouns wuli 'we' and cehuy 'we' with different formality in exhortatives. ${ }^{1}$
a. wuli-ka
salam-ul mantul-ca.
(firsthand exhortative)
1PL.NEU-NOM person-ACC make-EXHO
'Let us make man (in our image).' (Genesis 1: 26)
b. *ehuy-ka salam-ul mantul-ca
1PL.HUM-NOM person-ACC make-EXHO
Intended: 'Let us make man.'

An exhortative clause with a first-person neutral plural pronoun wuli 'we' is well-formed, as in (1a), while the clause with a first-person humble plural pronoun cehuy 'we' is ill-formed, as in (1b). Now consider secondhand exhortative clauses, as exemplified in (2). Formative mye (or myense) in (2) expresses the meaning 'you told me' by indicating the source of an anterior ex-

\footnotetext{
* I wish to express my deep gratitude to Leslie Saxon for her invaluable feedback and generosity. Thanks to Dianne Friesen for her editorial help. Remaining errors are mine. Authors: Hailey Hyekyeong Ceong, University of Victoria (haileyceong@gmail.com).

${ }^{1}$ The following abbreviations are used: ACC: accusative; ALLO: allocutive; ASSO: association; COMP: complementizer; CONJ: coordinator; DEC declarative; EVID: evidential; EXHO: exhortative; HON: honorific; HUM: humble; IMP: imperative; INT: interrogative; IRR: irrealis modal; NEU: neutral; NOM: nominative; PL: plural; PRES: present tense; PST: past tense; R: referring; SAP: speech act phrases; SG: singular; SUBJ: subject.
} 
hortative. ${ }^{2}$ The addressee of the current speech situation is the source of the anterior speech act and the speaker of the current speech situation was the goal of communication in the anterior exhortative. Mye (or myense) can express this meaning when it selects exhortative $c a$ as its complement even without an accompanying lexical verb of saying. ${ }^{3}$ Contrary to well-formed clauses (2a) and (2c), a secondhand exhortative clause with a first-person humble singular pronoun ce 'I' (2b) is ill-formed. Note the use of a dative case marker poko in secondhand exhortatives.
a. na-poko
seng-ul
mantul-ca-mye.
(secondhand exhortative)
1SG.NEU-DAT castle-ACC make-EXHO-HEARSAY
'(You told me) we should make a castle.'
b. *ce-poko seng-ul mantul-ca-mye.
1SG.HUM-DAT castle-ACC make-EXHO-HEARSAY
Intended: (You told me) we should make a castle.'
c. ce-poko seng-ul mantul-ca-myense-yo.
1SG.HUM-DAT castle-ACC make-EXHO-HEARSAY-ALLO
'(You told me) we should make a castle.'

In this paper, I argue that ( $1 b)$ and (2b) are syntactically ill-formed. In other words, the restriction against use of a first-person humble pronoun in (1b) and (2b) is not a matter of pragmatic. (That is, I do not agree with one who considers that this restriction is a matter of pragmatic and that therefore (2b) should be marked with \# instead of being marked with *.) Following the Duality of Person Hypothesis (Ritter and Wiltschko 2018) and relational formality features (Macaulay 2015, Portner et al. 2019), with some modifications, I argue that the ungrammaticality of clauses (1b) and (2b) can be explained by disagreement of phi features (either Spec-head or Probe-goal agreement). The first-person neutral pronouns wuli 'we' (1a) and $n a$ 'I' (2a) contrast with the first-person humble pronouns cehuy 'we' (1b) and ce 'I' (2b, 2c) in terms of formality. This contrast supports the view that pragmatic person features are lexicalized in Korean. Pragmatic person features are also encoded in clausal elements such as polite marker yo (Ceong and Saxon 2020). Thus, I argue that a formality feature associated with a null allocutive in (1a) and (2a) disagrees with a formality feature on cehuy (1b) and ce (2b). Instead, the formality of these pronouns agrees with polite yo, as shown in $(2 \mathrm{c})$.

The paper is structured as follows. In Section 2, I begin with a review of the Duality of Person Hypothesis and [STATUS] features of formality (Macaulay 2015). I detail the morphosyntactic property of formatives that encode formality features in Korean. In Section 3, by examining the interaction between exhortative $c a$ and first-person plural pronouns, I show that pragmatic person features reside in cehuy 'we', while grammatical person features reside in functional heads at the clausal level in Korean. In Section 4, I detail the properties of formative mye in secondhand exhortatives. In Section 5, a tentative syntactic structure of first-person pronouns and secondhand exhortatives is proposed that accounts for the data presented. In Section 6, I conclude with the idea that pragmatic person features, as well as formality status features, are dominant in Korean syntax.

\footnotetext{
${ }^{2}$ Formative mye and myense are interchangeable. Without yo, mye seems natural, while myense with yo is more natural to the author. We can find example clauses with mye-yo as well. Examining the distribution of mye and myense in corpus is required for future study.

${ }^{3}$ The clause would be ill-formed with a lexical verb. See the examples in (14).
} 
2. Pragmatic person and formality features. The Duality of Person Hypothesis (DPH henceforth) proposes that pragmatic person features are associated with a nominal speech act structure, whereas grammatical person features are associated with the traditional DP. For instance, it is proposed that kuani and eani in Ainu language which refer to the speaker and the addressee, respectively, are pragmatic person pronouns with the speech act layer, while $k a$ and ye in Waris language are realizations of grammatical features $[+1,-2],[-1,+2]$, respectively. Within DPH, pragmatic person features are primitive either [SPEAKER] or [ADDRESSEE], while grammatical person features are comprised of two binary features: $[+1,-2],[+1,+2],[-1,+2]$, and $[-1,-2]$. DPH also offers diagnostic criteria for distinguishing pragmatic person pronouns from grammatical ones. Table 1 presents the contrastive properties between grammatical and pragmatic person pronominals. Putting forward the idea that formality or familiarity expression like the T-V distinction in French is an indication of pragmatic person pronouns, Ritter and Wiltschko (2018) hypothesize that first-person inclusive pronouns $[+1,+2]$ and formality on pragmatic person features are in complementary distribution.

\begin{tabular}{lll}
\hline & Grammatical person & Pragmatic person \\
\hline Grammatical number & $\checkmark[ \pm$ plural $]$ (or associative) & $X$ (only associative plural) \\
\hline Grammatical gender & $\checkmark[ \pm$ feminine $], \ldots$ & $X$ \\
\hline $3^{\text {rd }}$ person & $\checkmark[-1,-2]$ & (to be determined) \\
\hline $1^{\text {st }}$ inclusive pronoun & $\checkmark[+1,+2]$ & $X$ speaker or addressee \\
\hline Formality distinctions & $X$ & $\checkmark$ \\
\hline
\end{tabular}

Table 1. Diagnosing grammatical vs. pragmatic person (Ritter \& Wiltschko 2018: 8)

In this paper, applying the diagnostics of pragmatic person features to Korean data, I investigate the clusivity of first-person plural pronouns wuli 'we (neutral)' and cehuy 'we (humble)' as well as their formality distinction. The syntactic consequences of the analysis are also discussed. I will show that formality in pronouns and the clusivity of $c a$ 'exhortative' are in complementary distribution in Korean.

Although Macaulay (2015) does not distinguish pronouns with pragmatic person features from those with grammatical person features and uses the person feature [1] instead of [SPEAKER], he argues that a Dynamic node with binary [ \pm STATUS] features of formality is needed above the Participant node in Harley and Ritter (2002)'s feature geometry. Despite his "informal survey" of verbal paradigms with formality across many languages, Macaulay (2015) is certain that formality features $[ \pm$ STATUS] that encode formal relationships between speech participants should be incorporated into a syntactic feature geometry. According to his survey, Bengali, Hindi, Italian, Japanese, Lyélé (Niger-Congo), Nepali, and Tamil are the languages that encode formality in the verbal paradigm. Verbal markers in these languages and the formality expressed by such elements are arguably governed by syntactic features that play a role in syntax, similar to how other phi features like PERSON, NUMBER, and GENDER are involved in syntax. By investigating the morphosyntactic properties of formality markers, Macaulay proposes three types of formality features in the grammar: 1) [+STATUS: $1>2,3$ ] indicating $1^{\text {st }}$ person with a higher status than $2^{\text {nd }}$ or $3^{\text {rd }}$ person; 2) [-STATUS: $1<2,3$ ] indicating $1^{\text {st }}$ person with a lower status than $2^{\text {nd }}$ or $3^{\text {rd }}$ person; and 3) [ \pm STATUS], unspecified in terms of formality. With the modification of these formality features and focusing on allocutivity, Ceong and Saxon (2020) also use formality features: i) [+STATUS: SPEAKER > ADDRESSEE ] means the grammatical Addressee has a lower status than the grammatical person Speaker; ii) [-STATUS: SPEAKER < ADDRESSEE ] means 
Addressee has a higher status than Speaker; and iii) [ \pm STATUS] indicates unspecified in terms of formality.

It is not difficult to find the evidence that [-STATUS: SPEAKER < ADDRESSEE ] is morphosyntactically marked in Korean. Formatives that realize the feature [-STATUS] are as follows: humble first-person singular pronoun $c e$ 'I', its plural form cehuy 'we', and allocutives - $p$ - and -yo (cf. Ceong and Saxon 2020). Moreover, when the subject carries [2] and [-STATUS], nouns such as siksa 'meal.HON' and honorific nominative -kkeyse as well as verbs such as tusi- 'eat.HON' or honorific subject agreement marker -si are morphologically marked in nominal and clausal domains. From the morphological point of view, Agree -si, noun siksa 'meal.HON', verb tusi'eat.HON', the pronouns ce 'I' and cehuy 'we', and polite - $p$ - and yo may be indistinguishable in terms of formality [-STATUS: $1<2,3]$ (cf. Macaulay 2015). However, their syntactic properties diverge. While Agree -si, noun siksa 'meal.HON', and verb tusi- 'eat.HON' can collocate with an honorific third-person subject without regard to the formality status of the addressee, the pronouns ce 'I' and cehuy 'we' and polite - $p$-and -yo are grammatical only if collocated with an honorific addressee feature.

Is formality feature [+STATUS: SPEAKER $>$ ADDRESSEE] also prominent in the way the feature [-STATUS: SPEAKER < ADDRESSEE] is marked? After close investigation of morphological encoding of nominals, pronominals, and verbal elements in terms of their formality, the evidence of encoding of formality feature [+STATUS: SPEAKER >ADDRESSEE] in the grammar is not apparent in the modern standard Korean. ${ }^{4}$ It seems that both [+STATUS: SPEAKER >ADDRESSEE] and [STATUS: SPEAKER =ADDRESSEE] are equally unmarked in syntax. Based on the asymmetric morphosyntactic encoding of [-STATUS: SPEAKER <ADDRESSEE] versus [ \pm STATUS: SPEAKER $\geq$ ADDRESSEE], I treat [ \pm STATUS] as an unspecified status feature that includes [+STATUS: SPEAKER $>$ ADDRESSEE] and [STATUS: SPEAKER =ADDRESSEE]. The examples that support my treatment can be found in clauses where the distribution of an honorific subject aligns with that of a neutral first-person subject. Consider a context where a male teacher is telling students that he will do something, as in (3).
a. sensayng-nim-i ha-l-key. teacher-HON-NOM do-IRR-COMP
'Teacher (=speaker) will do (it).'
b. nay-ka ha-l-key.
1SG.NEU-NOM do-IRR-COMP
'I will do (it).'
c. *sensayng-nim-kkeyse ha-si-l-key. teacher-HON-NOM.HON do-SUBJ.HON-IRR-COMP Intended: 'Teacher (=speaker) will do (it).'
d. sensayng-nim-kkeyse ha-si-n-ta-y. teacher-HON-NOM.HON do-SUBJ.HON-PRES-DEC-HEARSAY
'Teacher ( $\neq$ the speaker) said he was going to do (it).'

Although the subject in (3a) is a referential expression which differs from a first-person pronoun subject in (3b), the two clauses express the exact same proposition because the subject must be

\footnotetext{
${ }^{4}$ Even the first-person pronoun cim 'I ' referring to the King has a humble form kwain 'King (humble)' in classical Korean. The feature [+STATUS: SPEAKER $>$ ADDRESSEE] is possibly encoded in promissive $m a$ and the pronoun caney 'you' often used by older male speakers. This is a matter for further research.
} 
interpreted as the speaker or [+1, -2] under irrealis complementizer l-key (cf. Ceong 2019b); some R-expressions such as sensayng 'teacher' may be interpreted as referring to the speaker or addressee in certain contexts in Korean (cf. Ceong 2019b, Zanuttini et al. 2012). The point I want to make here is that even though sensayng is marked by the honorific title nim ' $\mathrm{Mr}$; $\mathrm{Mrs}$; Sir' so that the subject is attributed a higher status than the addressee in the clause, honorific nominative marker kkeyse and subject honorific agreement marker si are not only absent in the grammatical clause (3a) but also disallowed, as illustrated in (3c). In the declarative hearsay construction with ta-y, sensayng-nim has its usual third-person referential properties, and this allows the distribution of honorific nominative kkeyse and subject honorific Agree si, as illustrated in (3d). The identical distribution of sensayng-nim and neutral nay 'I' in l-key clauses (3a, b) and the contrasting distribution of sensayng-nim-kkeyse $(3 \mathrm{c}, \mathrm{d})$ show that reference options of [+STATUS: SPEAKER > ADDRESSEE] (as in (3a)) and [STATUS: SPEAKER = ADDRESSEE] (as in (3b)) can be overlapped or indistinguishable. Therefore, this study uses an updated version of Macaulay (2015)'s status features: 1) [-STATUS: SPEAKER < ADDRESSEE] means the addressee has a higher status than the speaker; and 2) [ \pm STATUS: SPEAKER $\geq$ ADDRESSEE] indicates that the context is unspecified in terms of formality between interlocutors. With these understandings in place, we turn to considering the formal properties of Korean pronouns.

3. Exhortatives and first-person plural pronouns. Korean exhortative clauses may or may not co-occur with an overt first-person plural pronoun. This section discusses the reasons why wuli 'we (neutral)' is compatible with exhortative ca but cehuy 'we (humble)' is not. In Korean, the directive illocution of exhortative can be either straightforwardly encoded in a morphological form $c a$ or through contextual interpretations of the interaction between multiple functional markers. For instance, unlike (4a), the interpretation of illocutionary force is 'potential' in clauses (4b) and (4c).
a. (wuli-ka) molayseng-ul mantul-ca.
1PL.NEU-NOM sandcastle-ACC make-EXHO
'Let's make a sandcastle.'
b. wuli-ka molayseng-ul kathi mantul-e-yo.
1PL.NEU-NOM sandcastle-ACC together make-COMP-ALLO
'Let's make a sandcastle together.'
c. molayseng-ul mantul-e.
sandcastle-ACC make-COMP
'Make a sandcastle!/(I'm) making a sandcastle.'

In (4a), formative $c a$ is the head of exhortative clauses and this formative solely expresses the directive illocution of exhortation, while in (4b), there is no such formative that directly encodes the illocution; it is constructed by the synergy from a combination of formatives, including pronoun wuli 'we', adverb kathi 'together', a non-finite verb, and allocutive marker yo. Allocutive $y o$ in (4b) indicates not only the speaker's politeness toward the addressee but also brings the addressee to the table. The absence of kathi 'together' and yo in (4c) yields less transparency of the interpretation of illocution and yields more dependency on pragmatic contexts. ${ }^{5}$ In (4a), re-

\footnotetext{
${ }^{5}$ Clause (4c) with a falling intonation can perform illocution acts of either commands or assertions; for instance, (4c) can be as an answer to a question "What are you doing?", then clause (4c) would perform an illocution act of assertions. Without such a context, the non-finite clause will be interpreted as a command.
} 
gardless of the presence of a first-person plural pronoun, the action mantul- 'make' is understood as a joint action by the speaker and the addressee, and the clause expresses the speaker's persuasive attitude towards the content or the addressee.

Exhortatives have been termed jussive clauses (Zanuttini et al. 2012) along with imperatives, which share a directive force but differ in person features on the null or overt subject of the clauses. The first-person plural pronoun is allowed in $c a$-jussive (5a) but not in la-jussive (5b).
a. (wuli)/*ne-ka
molayseng-ul
mantul-ca.
(jussive)
$1 \mathrm{PL} / 2 \mathrm{SG}-\mathrm{NOM}$
sandcastle-ACC
make-EXHO
'Let's make a sandcastle.'
b. (ne-ka) $/{ }^{*}$ wuli-ka molayseng-ul mantul-ela.
2SG/1PL-NOM sandcastle-ACC make-IMP
'Make a sandcastle.'

Based on the contrastive properties of $c a$ and $l a$, Zanuttini et al. (2012) propose that $c a$ is a head that carries an interpretable first-person inclusive feature [1 $\oplus 2]$, while $l a$ is a head that carries an interpretable second-person feature [2]. The agreement between person features of the head and of the subject in exhortative constructions has been considerably discussed in Zanuttini et al. (2012). However, a formality feature (dis-) agreement between the subject and the head of exhortative clauses is left out of the discussion. In this section, focusing on clusivity, I examine the agreement between the formality of the head and of the subject in exhortative constructions. Before discussing formality features of exhortative $c a$ and their agreement with the formality of the subject pronouns, I briefly review properties and distributions of first-person plural pronouns in Korean.

3.1. CLUSIVITY OF FIRST-PERSON PLURAL PRONOUNS. Similar to the situation in many languages, Korean first-person pronouns distinguish singular pronouns from plural ones. The first-person plural pronouns wuli 'we (neutral)' and cehuy 'we (humble)' are identified as identical in carrying features [1PL] (Sohn 1994; Siewierska 2004). In the discussion of person forms and social deixis across languages, citing Sohn (1994), Siewierska (2004) summarizes how Korean nounlike pronouns interact with so-called sentence enders. Siewierska points out that there are four categories of pronominals - Category I (Deferential, Polite) items, Category II (Blunt) items, Category III (Familiar, Intimate) items, and Category IV (Plain) items - despite six speech styles pertaining to clausal markers. Table 2, which is adapted from Siewierska (2004), presents the paradigm of Korean first-person pronouns, including the two kinds of first-person pronouns with different formality. Within first-person pronouns, however, there seem to be only two contrasts: Category I versus Category II, III, and IV. According to this system, the humble ce 'I' and cehuy 'we' occur with Category I clausal markers, whereas the neutral na 'I' and wuli 'we' occur with Category II, III, and IV clausal markers.

\begin{tabular}{llll}
\multicolumn{3}{r}{ SINGULAR } & \multicolumn{2}{c}{ PLURAL } \\
\hline$n a$ & $c e$ & wuli & cehuy \\
1SG & $1 \mathrm{SG}$ & 1PL & $1 \mathrm{PL}$ \\
II, III, IV & I & II, III, IV & I \\
\hline
\end{tabular}

Table 2. First-person pronoun paradigm in Korean (cf. Siewierska 2004: 232 Table 6.2) Citing examples from Sohn (1994), Siewierska (2004: 233 (38b)) shows the peculiar behaviour of humble ce 'I' which interacts with the covertly expressed addressee. Despite the interaction between pronoun $c e$ and the addressee, Korean has been considered as a language with no person 
agreement between pronominals and verbal/clausal items (cf. Baker 2008: 221, 246). Is there a syntactic consequence of pronominals with different formality in Korean? While it is obvious that wuli and cehuy share the same number feature PLURAL and different formality features, it is unclear if these pronouns carry the same property with respect to clusivity.

Sohn (1994: 283) states that wuli 'we' can be inclusive or exclusive, although the examples of such interpretations have not been fully given. The example that shows the exclusivity of wuli can be found in a clause headed by $l$-key where the periphrastic irrealis complementizer $l$-key restricts the subject to be exclusive $[+1,-2]$ (Ceong 2019b). Thus, the compatibility of $l$-key with wuli entails the exclusive reading of wuli. This is further supported by a grammatical clause with a coordinate DP that does not include the addressee, as shown in (6a).

$$
\begin{aligned}
& \text { a. wuli/Jenny-hako nay-ka molayseng-ul mantu-l-key. } \\
& \text { 1PL/Jenny-CONJ 1SG-NOM sandcastle-ACC make-IRR-COMP } \\
& \text { 'We/Jenny and I will make a sandcastle.' } \\
& \text { b. *wuli/*ne-hako nay-ka molayseng-ul mantu-l-key. } \\
& \text { 1PL/2SG-CONJ 1SG-NOM sandcastle-ACC make-IRR-COMP } \\
& \text { Intended: 'You and I will make a sandcastle.' }
\end{aligned}
$$

The pronoun wuli 'we' in (6a) can carry the meaning of me and someone other than you, as wuli 'we' can replace the coordinate DP subject consisting of the R-expression Jenny and the firstperson pronoun nay. Comparing to the exclusive reading of we (6a), the inclusive reading of wuli 'we' is not available in clauses with l-key, as shown in (6b). The coordinate DP, ne-hako nay 'you and me', with the inclusive meaning of you and me is disallowed as the subject of l-key clauses, as in (6b). That means, wuli 'we' cannot carry the meaning of you and me with l-key.

Now we turn over our attention to an inclusive interpretation of wuli in exhortatives and interrogatives. Under exhortative $c a$ and irrealis interrogative $l-k k a$, the inclusive reading of wuli is available. The well-formed clauses with the subject consisting of two pronouns ne 'you' and nay 'I' with the coordinator hako 'and' confirm the inclusivity of wuli, as in (7).
a. wuli/ne-hako nay-ka molayseng-ul mantul-ca.
1PL/2SG-CONJ 1SG-NOM sandcastle-ACC make-EXHO
'Let's make a sandcastle/you and I should make a sandcastle.'
b. wuli/ne-hako nay-ka molayseng-ul mantul-1-kka?
1PL/2SG-CONJ 1SG-NOM sandcastle-ACC make-IRR-INT
'Shall we/you and I make a sandcastle?'

Sohn's statement that wuli 'we' can be an inclusive or exclusive pronoun is confirmed. Can humble cehuy alternate between inclusive and exclusive readings? Neither Sohn (1994) nor Cysouw (2005) note the clusivity of cehuy. I argue that cehuy 'we' cannot express inclusivity and its interpretation is an exclusive first-person plural.
a. cehuy/Jenny-hako cey-ka
molayseng-ul mantu-l-key-yo.
1PL.HUM/Jenny-CONJ 1SG.HUM-NOM sandcastle-ACC make-IRR-COMP-ALLO
'We/Jenny and I will make a sandcastle.'
b. *cehuy/*tangsin-hako cey-ka molayseng-ul mantu-l-key-yo. 1PL.HUM /2SG-CONJ 1SG.HUM-NOM sandcastle-ACC make-IRR-COMP-ALLO Intended: 'You and I will make a sandcastle.' 
Semantically, cehuy as the humble plural subject excludes the honorific addressee. The pronoun cehuy requires an allocutive such as polite yo in the clause and expresses the meaning of 'humble me and humble someone other than you', as shown in Table 3.

\begin{tabular}{llll}
\hline pronoun & meaning & clusivity & TENSE-COMP-SAP \\
\hline cehuy & $\begin{array}{l}\text { humble me and humble someone } \\
\text { other than (honorific) you }\end{array}$ & exclusive & $\begin{array}{l}l-k e y-y o, * l-k e y \\
\text { ca-myense-yo, }{ }^{*} c a\end{array}$ \\
\hline wuli & me and someone other than you & exclusive & $l-k e y$ \\
\hline wuli & me and you & inclusive & $c a$ \\
\hline
\end{tabular}

Table 3. The interpretation of first-person plural pronouns and their compatibility

Have understood the morphosyntactic properties of two first-person plural pronouns with different formality, we turn to consider the incompatibility between the pronoun cehuy 'we' and the exhortative head $c a$.

3.2. EXCLUSIVE FIRST-PERSON PRONOUNS. Although the morphological property of wuli and cehuy may be equivalent to the English first-person plural pronoun we, I have shown that the morphosyntactic properties of wuli and cehuy differ. Based on the observation, I argue that cehuy 'we' carries [SPEAKER + ASSO] features which differ from wuli 'we' $[+1, \pm 2]$.

If my claim concerning the features [SPEAKER + ASSO], $[+1, \pm 2]$, and [1 $\oplus 2]$ are distinct in syntax is on the right track, the asymmetric compatibility of cehuy and wuli with ca in (9) can be explained. Wuli is compatible with $c a$ because it has unspecified [ \pm 2$]$ which can be valued by [1円2] on $c a$, while cehuy lacks [2] so it is incompatible with $c a$.
a. (wuli-ka) molayseng-ul mantul-ca.
1PL.NEU-NOM sandcastle-ACC make-EXHO
'Let's make a sandcastle.'
b. (*cehuy-ka) molayseng-ul mantul-ca.
1PL.HUM-NOM sandcastle-ACC make-EXHO
'Let's make a sandcastle.'

Through the use of the pragmatic person feature [SPEAKER], the incompatibility of cehuy with $c a$ in $(9 \mathrm{~b})$ can be accounted for in the domain of CP/ForceP/JussiveP. Alternatively, we also can speculate $\mathrm{ca}$ may carry formality features in addition to a first-person inclusive feature. For example, a formality feature [ \pm STATUS: SPEAKER $\geq$ ADDRESSEE ] on $c a$ disagrees with [- STATUS: SPEAKER $<$ ADDRESSEE ] on cehuy. I do not take this possibility to account for the disagreement between cehuy and $c a$ because the clusivity feature on $c a$ alone can account for the ungrammaticality. Moreover, there is no evidence that $c a$ itself encodes this formality feature. The interpretation of bare exhortative clauses concerning its formality comes from its c-selectional properties. Exhortative $c a$ cannot be selected by allocutive yo directly. Clauses (10a) and (10b) express the exact same proposition and same illocution force. The difference lies in the formality of the clauses. The formality of the clause (10b) is encoded in yo [-STATUS: SPEAKER < ADDRESSEE], while yo cannot select exhortative $c a$.
a. wuli-ka molayseng-ul kathi mantul-ca-(*yo).
1PL.NEU-NOM sandcastle-ACC together make-EXHO
'Let's make a sandcastle together.' 


\section{b. wuli-ka molayseng-ul kathi mantul-e-yo. \\ 1 PL.NEU-NOM sandcastle-ACC together make-COMP-ALLO \\ 'Let's make a sandcastle together.'}

The evidence to ensure the reliability of this conjecture is that there is a morphosyntactically designated position for an overt allocutive yo, as shown in the secondhand exhortative (11a).
a. molayseng-ul kathi mantul-ca-myense-yo.
sandcastle-ACC together make-EXHO-HEARSAY-ALLO
'(You told me) we should make a sandcastle together.'
b. *molayseng-ul kathi mantul-e-myense-yo.
sandcastle-ACC together make-COMP-HEARSAY-ALLO
Intended: '(you told me) we should make a sandcastle together.'

We can consider, on the basis of the facts in (10), that $c a-\emptyset$ and $e-y o$ are in complementary distribution in exhortative constructions in terms of formality. If we conjecture that pragmatic person and formality features are represented in the syntax, the asymmetric behaviour of firstperson plural pronouns in (9) can be explained as a rule-based phenomenon.

3.3. THE DUALITY OF PERSON HYPOTHESIS. I conclude this section with the application of firstperson plural pronouns to the diagnostics suggested by DPH. Table 4 is an excerpt from Table 2 which suggests that first-person inclusive pronoun $[+1,+2]$ and formality on pragmatic person features are in complementary distribution.

\begin{tabular}{lll}
\hline & Grammatical PERSON & Pragmatic PERSON \\
\hline $1^{\text {st }}$ inclusive pronoun & $\checkmark[+1,+2]$ & $X$ SPEAKER or ADDRESSEE \\
\hline Formality distinctions & $X$ & $\checkmark$ \\
\hline
\end{tabular}

Table 4. Diagnosing grammatical vs. pragmatic person (cf. Ritter \& Wiltschko 2018: 8)

DPH makes correct predictions regarding the distinct properties of pragmatic person features from grammatical person features. As we have discussed in this section, the first-person inclusive $[+1,+2]$ is associated with the head $c a$ and pronoun cehuy with a formality feature is only referring to the speaker. This is shown in Table 5.

\begin{tabular}{lll}
\hline & Grammatical PERSON & Pragmatic PERSON \\
\hline & wuli $[+1, \pm 2]$ & \\
\hline $1^{\text {st }}$ inclusive feature & $\checkmark c a[+1,+2]$ & $X$ \\
\hline Formality distinctions & $X$ & $\checkmark$ cehuy ([SPEAKER+ASSO]) \\
& & $\checkmark$ and \\
& & $\checkmark$ chuy [-STATUS: SPEAKER $<$ ADDR] \\
\hline
\end{tabular}

Table 5. Grammatical vs. Pragmatic person features in Korean

So far, I have shown that binary grammatical features alone cannot account for the unequal distribution of first-person pronouns in exhortative constructions.

4. Evidence from secondhand speech act markers. Traditionally the feature PERSON that resides in pronominals, clitics, or verbal elements realizes phi agreement by interacting with NUMBER and GENDER across languages. Recently, it was also observed that feature PERSON is encoded in finite and non-finite complementizers (Bennis 2006, Carstens 2005, Hasegawa 2009) and evidentials (AnderBois 2019, Speas 2004). Along the lines of these studies, it is argued that 
jussive heads (Zanuttini et al. 2012), irrealis complementizers (Ceong 2019b), hearsay evidentials (Ceong 2016, Lee 2019), and allocutives (Ceong and Saxon 2020) also encode feature PERSON in Korean. In this section, we investigate the distribution and meaning of mye in the context of secondhand speech acts. ${ }^{6}$ When formative mye selects exhortative $c a$, it creates a secondhand exhortative. This is shown in (12).

$$
\begin{aligned}
& \text { molayseng mantul-ca-mye. } \\
& \text { sandcastle make-EXHO-HEARSAY } \\
& \text { '(You told me) we should make a sandcastle.' }
\end{aligned}
$$

The formative mye in (12) implies there was an anterior speech act that was uttered by the addressee of the current speech act. It also implies that the speaker of the current speech act was the person who had received the anterior speech act, that is the addressee. Therefore, mye expresses 'you told me XP' where XP represents one of $\mathrm{CP} /$ ForceP/JussiveP/LinkingP depending on one's assumption about the projection encoding a clause-typing marker such as exhortative $c a$ (cf. Ceong 2019a). To compare the elusive meaning of mye with the English equivalent translation you told me, I provide a context where mye would be used. Suppose on the way to the beach Nina's friend told Nina they should make a sandcastle (e.g., "molayseng-ul mantulca 'Let's make a sandcastle",, Nina's friend told Nina.). After they arrived at the beach, Nina started making a sandcastle. Then, Nina's friend asks, "What are you doing?". Then Nina would say clause (12) to her friend because her action was initiated by her friend's word, so the question was somewhat unexpected.

There are two formatives that contrast with mye in secondhand speech acts in Korean: hearsay $y$ and echo ko. These formatives are not interchangeable and are associated with a speech act role in the anterior and current speech acts, as shown in grammatical (13a, 13b) and ungrammatical clauses $(13 \mathrm{c}, 13 \mathrm{~d}) .^{7}$
a. Nina-ka molayseng mantul-ca-y.
Nina-NOM sandcastle make-EXHO-HEARSAY
'Nina (told me) we should make a sandcastle.'
b. molayseng mantul-ca-ko.
sandcastle make-EXHO-REINFORCEMENT
'(I said) we should make a sandcastle!'
c. *Nina-ka molayseng mantul-ca-mye.
Nina-NOM sandcastle make-EXHO-HEARSAY
Intended: '(Nina told me) we should make a sandcastle.'

\footnotetext{
${ }^{6}$ Although Ahn and Yap (2015) treat tako, tamye, and tamyense as monomorphemic evidentials, I analyze ko, mye, and myense as morphemes distinct from declarative $t a$ because they can take other kinds of clause-typing markers as their complement, such as interrogative nya.

${ }^{7}$ When mye selects declarative ta, the speaker of the anterior (firsthand) exhortative and the addressee of the current secondhand exhortative do not need to be co-indexed if the clause has a question force with a rising intonation.
(1) ne khaynata ka-n-ta-mye?
you Canada go-PRES-DEC-HEARSAY
'I heard you are going to Canada, is that right?'

Except in this one case, even with a falling intonation or with interrogative nya, the secondhand mye expresses 'you told me'. I do not have a good explanation for why mye has an alternative meaning only with declarative ta with a rising intonation. However, even in the exceptional case of declarative $t a$ with a rising intonation, I sense that the content of the proposition needs to be related to the addressee.
} 


\section{d. *molayseng mantul-ca-mye. sandcastle make-EXHO-HEARSAY \\ Intended: '(I said) we should make a sandcastle.'}

Given the interpretation and the contrasting elements with mye in the context of secondhand speech acts, I present the details of mye. First, hearsay mye cannot be embedded by matrix clauses with lexical verbs of saying, as in (14a) and (14b). The subordinating complementizer ko directly selects the exhortative head in well-formed clauses, as in (14c).
a. *ne-ka [ka-ca-mye] malhay-ss-ta.
2SG-NOM go-EXHO-HEARSAY say-PST-DEC
Intended: 'You said we should go.'
b. *ne-ka [ka-ca-mye]-ko hay-ss-canh-a.
2SG-NOM go-EXHO-HEARSAY-COMP do-PST-EVID-COMP
Intended: 'You said we should go.'
c. ne-ka [ka-ca]-ko hay-ss-canh-a.
2SG-NOM go-EXHO-COMP do-PST-EVID-COMP
'You said we should go.'

The unembeddable property of hearsay mye suggests that the structural position of mye must be higher than a matrix CP. Second, mye introduces a dative goal argument marked by a dative case marker poko 'to', as in (15b). In secondhand exhortative constructions, only first-person or the speaker can be marked by the dative, as shown in ill-formed clauses with the third- and secondperson goal arguments (15c).
a. ka-ca-mye.
go-EXHO-HEARSAY
'(You told me) we should go.'
b. na/wuli-poko
ka-ca-mye
1SG.NEU/1PL.NEU-DAT go-EXHO-HEARSAY
'(you told me/us) we should go.'
c. *kyay/*Minho/*ne-poko ka-ca-mye
3SG/Minho/2SG-DAT go-EXHO-HEARSAY
'Intended: (You told him/Minho/you) he/they/yourself should go (with you).'

Although the addressee in a direct/firsthand imperative is also a goal of communication, the addressee cannot be overtly realized as a syntactic argument, as shown in (16a). This contrasts with the legitimate overt first-person goal argument marked by a dative in (16b) where wuli 'the speaker with their association' or $n a$ 'I' behaves like a goal of communication. ${ }^{8}$
a. *ne-poko ka-la.
2SG-DAT go-IMP
Intended: '(I'm telling you) Go.'
b. wuli/na/*ne-poko ka-la-mye.
1PL/1SG/2SG-DAT go-IMP-HEARSAY
'(you told us/me/you) we/I/you should go.'

\footnotetext{
8 The addressee can be marked by a goal dative in secondhand imperatives with hearsay $y$ and a rising intonation.

(1) Ne-poko ka-la-y? you-DAT go-IMP-HEASAY '(Did he/she/they told you) you should go?
} 
It is evident that the legitimate person feature on dative arguments in mye-hearsay construction is restricted to be either $[+1,-2]$ or SPEAKER. Contrary to the compatibility of a first-person neutral dative argument $n a$ 'me' with ca-mye (16b), the first-person humble dative argument ce 'me' is disallowed in (16a) but allowed in ca-mye clauses with allocutive yo (17b). That is, $c e$ 'me (humble)' is compatible with the honorific addressee indexed by polite $y o$.
a. na/*ce-poko
1SG.NEU/1SG.
ka-ca-mye
1SG.NEU/1SG.HUM-DAT go-EXHO-HEARSAY
b. ce/*na-poko
we should go.'
1SG.HUM/1SG.NEU-DAT go-EXHO-HEARSAY-ALLO
'(You told me) we should go.'

Like $c a$, I assume that it is not mye itself that encodes a formality feature in (17). I suggest that a null allocutive (non-honorific) that is associated with the domain above mye in the structure restricts the feature on a dative argument to be a neutral, as illustrated in the well-formed clause (16a).

In sum, I have shown that in addition to the heads of jussive clauses which contain person features (cf. Zanuttini et al. 2012), the heads of secondhand speech act phrases also carry person features. By selecting a jussive head, including exhortative $c a$, the hearsay head mye licenses and restricts person features on a goal dative argument. Mye differs from lexical verbs of saying, including malhata 'say, tell, talk, speak', hayssta 'said', or kulayssta 'said so'. Unlike lexical or auxiliary verbs, mye expresses an anterior speech event without co-occurring with a past tense marker and a subordinating complementizer ko. In interactional communication, mye 'you told me' can simultaneously express two speech acts that are uttered in two different deictic spheres.

5. Syntactic representation of secondhand exhortatives. In Section 3 it was demonstrated that the exhortative $c a[+1,+2]$ is compatible with the first-person plural subject wuli $[+1, \pm 2]$ but not with cehuy [SPEAKER+ASSO]. In Section 4 it was shown that ca-mye is compatible with the oblique na 'I' (or wuli) but not with humble ce 'I' (or cehuy). When ca-mye (or ca-myense) is selected by allocutive yo, humble ce 'I' (or cehuy) is allowed. Consider again the examples in (18) and (19) which illustrate the systematic concordance of pronominal and clausal formatives.
a. (wuli-ka) nolay-lul pwulu-ca.
1PL.NEU-NOM song-ACC sing-EXHO
'Let's sing a song.'
b. *cehuy-ka nolay-ul pwulu-ca
1PL.HUM-NOM sing-ACC sing-EXHO
Intended: 'Let's sing a song.'
1SG.NEU/1SG.HUM-DAT together do-EXHO
'(You told me) we should do (it) together.'
b. ce/*na-poko kathi ha-ca-myense-yo.
1SG.HUM/1SG.NEU-DAT together do-EXHO-ALLO
'(You told me) we should do (it) together.'
a. na/*ce-poko kathi ha-ca-mye. (secondhand exhortative)

Based on the discussion of the relevant data for pragmatic person features, below I will propose a structure for the data presented in (18) and (19). Following the studies proposing that there are two syntactic domains above CPFORCE, which are SAP and saP (Haegeman and Hill 2013, Speas 
and Tenny 2003) or Grounding and Responding Spines (Ritter and Wiltschko 2020), this section explores how clausal formatives ca-mye-yo and first-person pronominals are represented in the structure. The current section has two components. First, following DPH, I provide the structure of Korean first-person pronouns. Second, the structural representation of secondhand exhortatives is hypothesized.

DPH (Ritter and Wiltschko 2018) proposes that there are three different kinds of internal structure for pronominals: i) pragmatic person pronouns with a speech act layer; ii) grammatical person pronouns without a speech act layer; and iii) grammatical person pronouns with a silent speech act layer. As Korean pronouns are never used impersonally, like Japanese pronouns, they are not grammatical persons, according to DPH. The interpretation of impersonal null subjects in Korean is given by Portner et al. (2019: 8 (20)) based on la-imperative examples. I propose that humble ce and cehuy are pragmatic person pronouns that are directly associated with a speech act layer, while na and wuli are grammatical person pronouns with silent speech act layers.

a. pragmatic first person pronouns

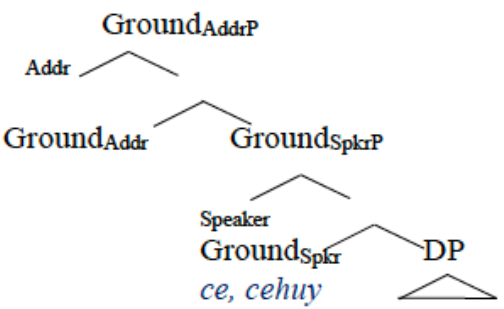

b. grammatical person pronouns with silent speech act layer

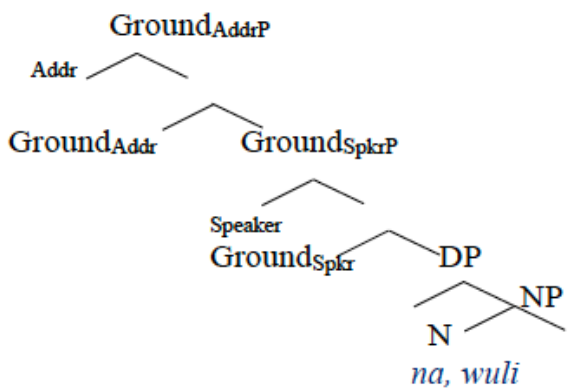

For the structure of clausal items, I follow an interactional layer of structure (Ritter and Wiltschko 2020: 15 (39)). I argue that the dative argument of secondhand exhortatives is originated inside of interactional layers. The structure of ca-mye clauses may be represented as (21).

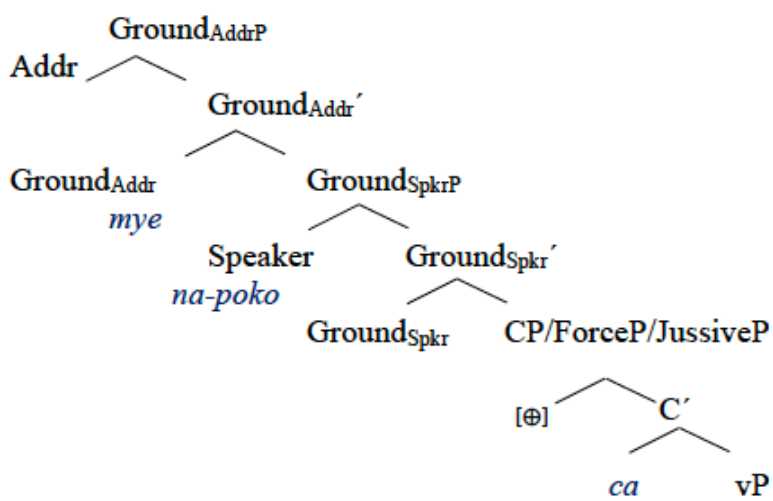

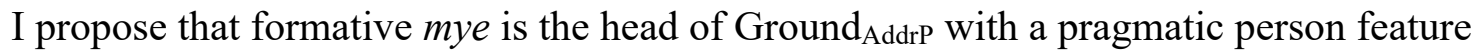

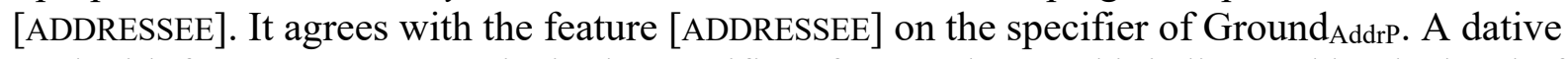
goal with feature [SPEAKER] sits in the specifier of GroundspkP and it is licensed by the head of

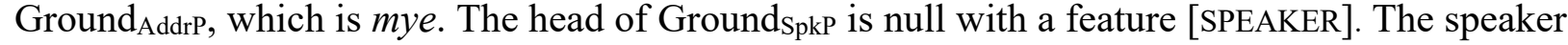
of the current speech act is associated with the head of Ground ${ }_{S p k P}$, which agrees with the dative goal argument with feature [SPEAKER]. The specifiers and the heads of Ground ${ }_{\text {AddrP }}$ and Ground- 
SpkP are scoped by either allocutive yo [-STATUS: SPEAKER $<$ ADDRESSEE] or a null allocutive [ \pm STATUS: SPEAKER $\geq$ ADDRESSEE]. The allocutivity and hearsay mye (or myense) scope over the whole JussiveP with the head $c a$ and the specifier [ $\oplus$ ] expressing an exhortative speech act. The respective order of constituents ca-myense-(yo) is completely fixed, nothing can appear between the constituents. Thus, the head mye takes scope over the dative argument na-poko 'to me' which is the speaker of the current speech act and included in the meaning of 'you told me'. The dative argument is unavailable in direct exhortatives because a secondhand speech act phrase is absent. Given the structure of pronominal and clausal items, I argue that the ungrammaticality of (18b) is due to the mismatch between a formality feature on the specifier of GroundspkP and the feature

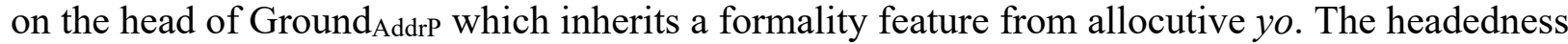
of secondhand speech act formatives, including hearsay $y$ as well as allocutive yo, is discussed in Ceong (2019a), mainly based on their c-selectional properties and contrastive meanings.

6. Conclusions. In this paper, our concern has been the nature of pragmatic person features which encode the speech act roles of discourse participants, in light of the behaviour of firstperson plural pronouns, exhortatives, and hearsay mye in Korean. The standard explanation attributes the incompatibility of exhortative $c a$ with cehuy 'we' to pragmatics. By suggesting that the traditional grammatical person features 1PL or $[+1,+2]$ alone cannot account for the unequal distribution of wuli 'we (neutral)' and cehuy 'we (humble)', I have developed a syntactic explanation for the restricted distribution of cehuy in direct/firsthand exhortatives. Based on the legitimacy of hearsay mye and a dative argument in root clauses with the meaning you told me without an accompanying lexical verb of saying, I argue that speech act phrases above JussiveP are needed to account for their distribution and the restricted distribution of ce 'me (humble)' as a dative argument. Drawing on insights from Macaulay (2015) and Ritter and Wiltschko (2018), I have argued that pragmatic person and formality features play a significant role in Korean morphosyntax. Although I only investigate exhortatives in this study, I conjecture that the properties of pragmatic person and formality features can apply to hearsay imperative clauses as well as hearsay interrogatives (cf. Ceong 2016).

\section{References}

Ahn, Mikyung \& Foong Ha Yap. 2015. Evidentiality in interaction: A pragmatic analysis of Korean hearsay evidential markers. Studies in Language 39(1). 46-84. https://doi.org/10.1075/s1.39.1.03ahn.

AnderBois, Scott. 2019. At-issueness in direct quotation: The case of Mayan quotatives. Semantics and Linguistic Theory (SALT) 29. 371-391. https://doi.org/10.3765/salt.v29i0.4623.

Baker, Mark. 2008. The syntax of agreement and concord. Cambridge: Cambridge University Press. https://doi.org/10.1017/CBO9780511619830.

Bennis, Hans. 2006. Agreement, pro and imperatives. In Peter Ackema, Patrick Brandt, Maaike Schoorlemmer \& Fred Weerman (eds.), Arguments and agreement.101-123. New York: Oxford University Press.

Carstens, Vicki. 2005. Agree and EPP in Bantu. Natural Language \& Linguistic Theory 23(2). 219-279. https://doi.org/10.1007/s11049-004-0996-6.

Ceong, H. Hyekyeong. 2016. Korean hearsay constructions and speech acts. In Lindsay Hracs (ed.), 2016 CLA conference proceedings. Ottawa: Canadian Linguistics Association. https://cla-acl.artsci.utoronto.ca/actes-2016-proceedings/. 
Ceong, H. Hyekyeong. 2019a. The morphosyntax of clause typing: Single, double, periphrastic, and multifunctional complementizers in Korean. Victoria, BC: University of Victoria dissertation. http://hdl.handle.net/1828/10815.

Ceong, H. Hyekyeong. 2019b. The PERSON restriction on periphrastic irrealis complementizers and the interpretation of subject pro. Canadian Journal of Linguistics/Revue Canadienne de Linguistique 64(4). 753-760. https://doi.org/10.1017/cnj.2019.23.

Ceong, H. Hyekyeong \& Leslie Saxon. 2020. Addressee honorifics as allocutive agreement in Japanese and Korean. In Angelica Hernández \& M. Emma Butterworth (eds.), 2020 CLA conference proceedings. Ottawa: Canadian Linguistics Association. https://cla-acl.artsci.utoronto.ca/actes-2020-proceedings/.

Cysouw, Michael. 2005. A typology of honorific uses of clusivity. In Elena Filimonova (ed.), Clusivity: Typology and case studies of inclusive-exclusive distinction. 213-230. Amsterdam: John Benjamins Publishing. https://doi.org/10.1075/ts1.63.

Haegeman, Liliane \& Virginia Hill. 2013. The syntacticization of discourse. In Raffaella Folli, Christina Sevdali \& Robert Truswell (eds.), Syntax and its limits, 370-390. Oxford: Oxford University Press.

Harley, Heidi \& Elizabeth Ritter. 2002. Person and number in pronouns: A feature-geometric analysis. Language 78(3). 482-526. https://doi.org/10.1353/lan.2002.0158

Hasegawa, Nobuko. 2009. Agreement at the CP level: Clause types and the 'person' restriction on the subject. In Reiko Vermeulen \& Ryoskuke Shibagaki (eds.), Proceedings of the 5th Workshop on Altaic Formal Linguistics (MITWPL 58), 133-152. http://mitwpl.mit.edu/catalog/mwp158/.

Lee, EunHee. 2019. Korean syntax and semantics. Cambridge: Cambridge University Press.

Macaulay, Benjamin Kirkland. 2015. The morphosyntax of formality: A typology and inclusion in feature geometry. University of Pennsylvania Working Papers in Linguistics 21(1). 18. https://repository.upenn.edu/cgi/viewcontent.cgi?article=1847\&context=pwpl.

Portner, Paul, Miok Pak \& Raffaella Zanuttini. 2019. The speaker-addressee relation at the syntax-semantics interface. Language 95(1). 1-36. https://muse.jhu.edu/article/719230.

Ritter, Elizabeth \& Martina Wiltschko. 2018. Distinguishing speech act roles from grammatical person features. In Emily Dmyterko (ed.), 2018 CLA conference proceedings. Ottawa: Canadian Linguistics Association. https://cla-acl.artsci.utoronto.ca/actes-2018-proceedings/.

Ritter, Elizabeth \& Martina Wiltschko. 2020. Interacting with vocatives. In Angelica Hernández \& M. Emma Butterworth (eds.), 2020 CLA conference proceedings. Ottawa: Canadian Linguistics Association. https://cla-acl.artsci.utoronto.ca/actes-2020-proceedings/.

Siewierska, Anna. 2004. Person. Cambridge: Cambridge University Press.

Speas, Penny \& Carol Tenny. 2004. Configurational properties of point of view roles. In Anna M. Di Sciullo (ed.), Asymmetry in grammar, 315-344. Amsterdam: John Benjamins Publishing.

Speas, Margaret. 2004. Evidential paradigms, world variables and person agreement features. Italian Journal of Linguistics 16(1). 253-280.

Sohn, Ho-Min. 1994. Korean. New York: Routledge.

Zanuttini, Raffaella, Miok Pak \& Paul Portner. 2012. A syntactic analysis of interpretive restrictions on imperative, promissive, and exhortative subjects. Natural Language \& Linguistic Theory 30(4). 1231-1274. https://doi.org/10.1007/s11049-012-9176-2. 